EPiC Series in Engineering
Volume 3, 2018, Pages 901-907
HIC 2018. 13th International
Conference on Hydroinformatics

\title{
Applicability of the Deep Learning Flood Forecast Model against the Inexperienced Magnitude of Flood
}

\author{
Masayuki Hitokoto ${ }^{1}$ and Masaaki Sakuraba ${ }^{1}$ \\ ${ }^{1}$ Research and Development Center, Nippon Koei Co., Ltd. \\ hitokoto-ms@n-koei.jp, sakuraba-ms@n-koei.jp
}

\begin{abstract}
Although artificial neural networks (ANN) is widely used for real-time flood prediction model, it is pointed out that the weak point of the model is poor applicability for the inexperienced magnitude of flood. In this study, the ANN models were applied to first-grade rivers in Japan, Tokoro River catchment and Abashiri River catchment. The training data of the ANN models were all the rainfall-runoff event which exceeded the Flood Watch Water Level during the period of 1998-2015. Types of observation data were river-stage and rainfall at 1-hour pitch. The validation data was the largest flood since the river-stage observation had started. The main component of the model was the four-layer feed-forward network. As a network training method, the deep learning based on the denoising autoencoder was applied. The output of the neural network was change in river-stage in $\mathrm{T}$ hours at the prediction point. The input data was the upstream river-stage, hourly change in river-stage and hourly rainfall. The riverstage prediction up to 6 hours showed very good accuracy, and It was proved that it can be nicely predicted even for the past largest flood.
\end{abstract}

\section{Introduction}

Improvement of the accuracy of flood forecasting is critical in reducing the damage that can occur during flood disasters. Although the flood prediction system is in operation in the first class rivers in Japan, prediction accuracy is insufficient in many cases for residents' appropriate evacuation judgment. While most of the prediction system is composed of the physically based or conceptually lumped rainfall-runoff model, ANN models are acknowledged as robust flood-forecasting models that can be applied to a wide range of river systems (ASCE Task Committee on Application of Artificial Neural Networks in Hydrology, Dawson, Maier). As a new method of ANN, deep learning has been proposed. By using deep learning, the model itself extracts essential information from a big amount of input data. Deep learning is being studied in various fields such as image recognition, speech 
recognition, natural language processing and so on. Recently, the real-time river-stage prediction method had been developed by using deep learning, and reported the better result than the conventional ANN model and other physically-based or statistical prediction models (Hitokoto). As a weak point of the ANN river-stage prediction model, though, the prediction accuracy for the inexperienced flood scale can not be guaranteed (Dawson). This is a big problem from the standpoint of disaster prevention. In this study, we will examine the applicability of ANN river-stage prediction model trained by deep learning (Hinton) for the case of the past largest flood case that occurred in Typhoon No. 10 in 2016.

\section{Material and methods}

\subsection{Artificial Neural Network}

The feed-forward neural network is composed of input layer, hidden layer, and output layer, as shown in Fig 1. The architecture of a single neuron is also shown in Fig 1. Each neuron computes the data according to the following equations:

$$
z=f(u) \quad\left(u=\theta_{i}+\sum_{i=1}^{K} w_{i} x_{i}\right)
$$

Here, $u$ is the weighted sum of all inputs to a neuron, $x$ is the input, $w$ is the network weight, $\theta$ is the bias, $z$ is the output of the neuron, $K$ is the number of inputs to each neuron, and $f(u)$ is the activation function. In this paper, we redefine that the bias is included in the parameter vector $w$. While there are many types of activation functions, we used sigmoid function, which has been most frequently used in conventional ANN. In the learning process, the ANN optimizes all of the network weights to minimize the error in the network's output and the training data - normally observation data. In this study, root mean error $E$ was used to evaluate the error.

$$
E(w)=\frac{1}{2} \sum_{n=1}^{N}\left(d_{n}-y\left(x_{n} ; w\right)\right)^{2}
$$

Here, $N$ is the number of sample data, $d$ is the desired data, and $y$ is the output of the network. By iteratively applying the gradient decent method to the randomly preset initial network weight $(w)$, we obtain the optimized $w$, which minimizes the $E$. In the gradient decent method, $w$ is updated by the following equation:

$$
w^{(t+1)}=w^{(t)}-\varepsilon \nabla E
$$

Here, $\varepsilon$ is the learning rate, which decides the amount of updating of $w$. Superscript $t$ is the number of iterations. To apply the gradient decent method, we have to obtain the gradient of the objective function, $\nabla E$. In this study, we apply back propagation method (Rumelhart) to obtain $\nabla E$. 

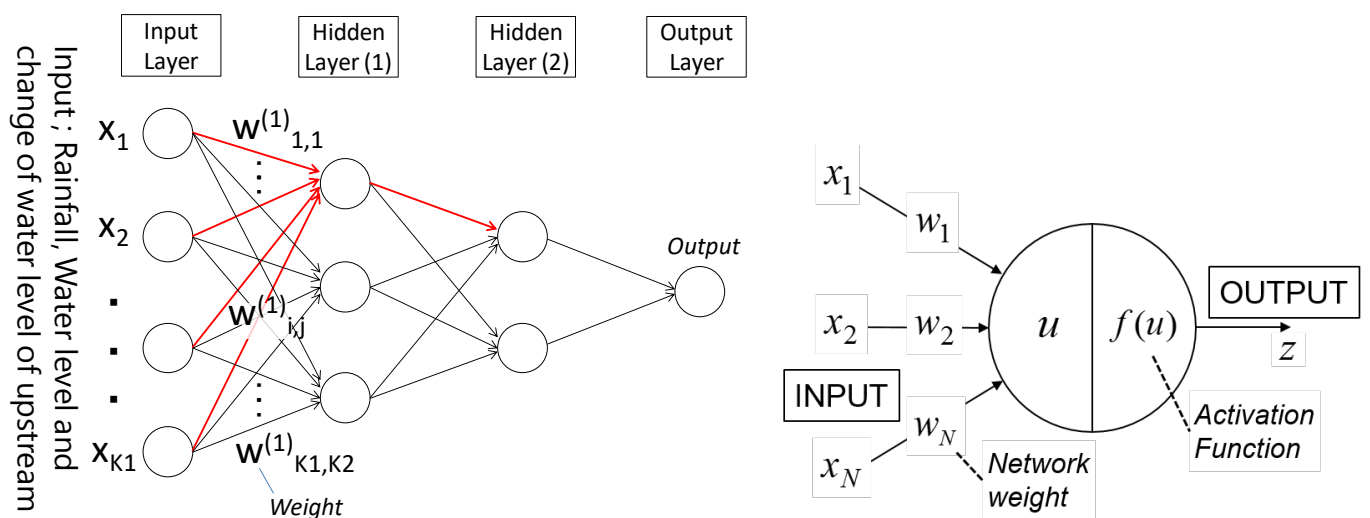

Figure 1: Schematic image of feed-foreword artificial neural network and its single unit

\subsection{Deep learning}

To utilize as many observation data as possible for input of the ANN, it is necessary to increase the expressive power of the network. Though expressive power can be increased by adding hidden layer, learning processes become difficult in the deep network owing to the vanishing gradient problem. In this study, the network was pre-trained with autoencoder. Autoencoder optimizes the network weight so as to equal the input and output. Then, the result of optimized network weight is used as the initial network weight of the whole ANN model.

Stochastic gradient descent method was applied for optimizing process. Learning late was set by AdaGrad. When updating the network weight, momentum was used to diminish the fluctuation in weight changes over consecutive iterations. To prevent over-fitting, dropout was applied.

\subsection{Study basin and hydrological data}

The study area 1 is the Abashiri River, in the Hokkaido Island, Japan. The location of the riverstage gauging stations and rain-gauge stations are shown in Figure 2a. 6 rain-gauge stations and 4 water level gauging stations, without missing or error data, were used for the training. In the figure, the locations of the river-stage gauging stations are drawn as triangles, and the rain gauges as circles. The prediction point in this study is Kawajiri-Gyojo, located in the lowest point of the study area. There is no big dam or other flood control facility. The study area 2 is the Tokoro River, also in the Hokkaido Island, Japan. The prediction point is Kawakamizoi, as shown in Figure $3 b$.

\subsection{Case Study}

The condition setting of the inputs and outputs is shown in Table 2. In each case study, prediction time is 1 to 6 hours. 6 ANN models were developed according to the prediction time. Input data was set up to include as much data as possible, which can affect the river stage prediction. In case future time rainfall data is required, observed data was used to resemble prediction rainfall. 


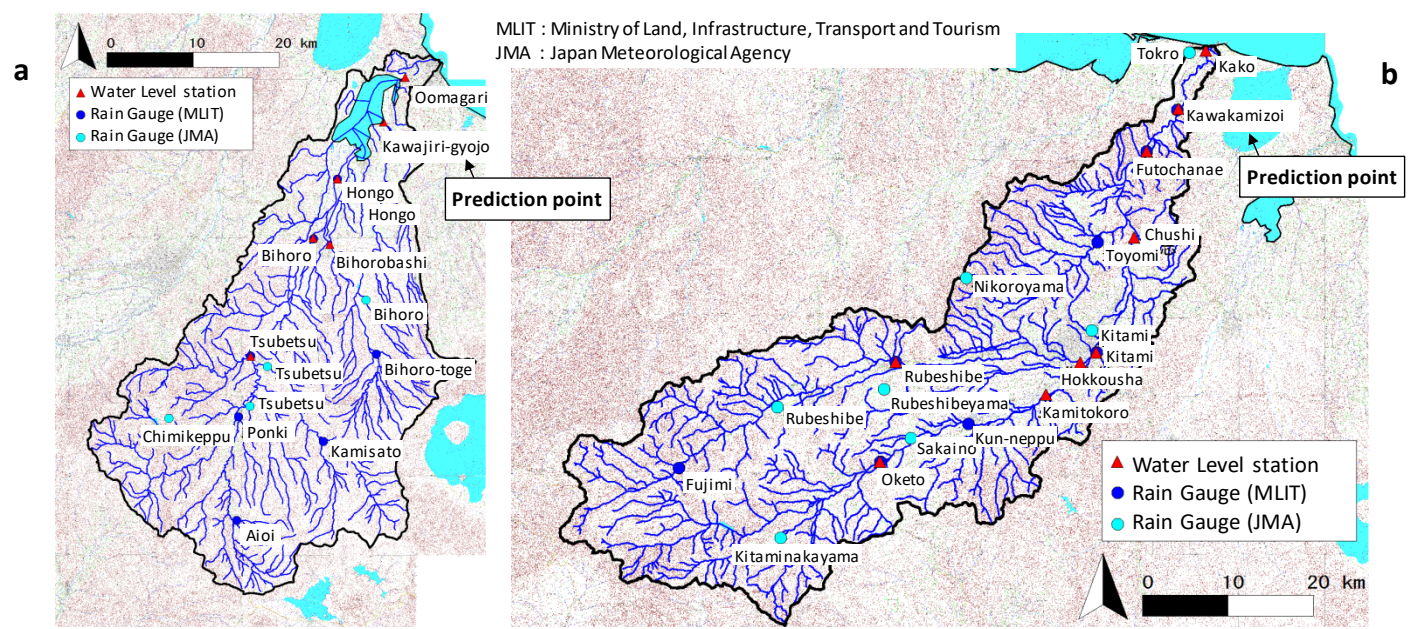

Figure 2: The location map of water level station and rain gauge of Abashiri River and Tokoro River

\begin{tabular}{ccccccc}
\hline $\begin{array}{c}\text { River } \\
\text { name }\end{array}$ & Prediction point & $\begin{array}{c}\text { Basin } \\
\text { area }\left(\mathrm{km}^{2}\right)\end{array}$ & $\begin{array}{c}\text { Number } \\
\text { of water } \\
\text { level } \\
\text { station }\end{array}$ & $\begin{array}{c}\text { Number } \\
\text { of } \\
\text { raingauge }\end{array}$ & $\begin{array}{c}\text { Number of } \\
\text { Objective } \\
\text { flood }\end{array}$ & $\begin{array}{c}\text { Objective } \\
\text { period }\end{array}$ \\
\hline $\begin{array}{c}\text { Abashiri } \\
\text { Tokoro }\end{array}$ & $\begin{array}{c}\text { Kawajiri-Gyojo } \\
\text { Kawakamizoi }\end{array}$ & 1319.0 & 4 & 6 & 17 & $1998-2016$ \\
\hline
\end{tabular}

Table 1: Basic characteristics of the catchment under study

\begin{tabular}{c|cc|cc|c}
\hline \multicolumn{5}{c|}{ Input } & \multirow{2}{*}{ Output } \\
\hline Type & \multicolumn{2}{c}{ Number of station used } & \multicolumn{2}{c}{ Time } & \\
\hline $\begin{array}{c}\text { Hourly water level } \\
\text { Hourly change in } \\
\text { water level }\end{array}$ & 1 & 1 & $-1,0$ & $-1,0$ & \multirow{2}{*}{ Change } \\
$\begin{array}{c}\text { Hourly rainfall } \\
\text { Total number of } \\
\text { input }\end{array}$ & 6 & 5 & -15 to -7 & -8 to -1 & in water \\
level \\
in t \\
hours.
\end{tabular}

Table 2: Condition setting of inputs and output of $t$ hours prediction model

\section{Result and Discussion}

\subsection{Prediction Results and the analysis of the data}

All the training data, validation data and the predicted result of deep learning model are shown in Fig 3 (Tokoro River) and Fig 4 (Abashiri River) as scatter diagrams. The result of the 6 hours prediction by the deep learning model was shown in Fig 5 (Tokoro River) and Fig 6 (Abashiri River) as the hydrographs. Fig 5 and Fig 6 showed good prediction accuracy in all the flood period. 
Especially in Abashiri, the river-stage fluctuation is more gentle, result in the better result. Generally, the lack of the applicability for the inexperienced flood scale is mentioned to one of the biggest weak point of the ANN river-stage prediction model and other machine learning based model. In other words, ANN model demonstrates good ability to interpolate the result of new event from the training events, and is not good at extrapolate. However, this study shown the good applicability of prediction for the largest flood event, which is larger among all the training flood.

According to the Fig 3 and Fig 4, validation flood is certainly the largest in terms of the river-stage. However, in terms of "6 hourly change" in river-stage, the validation flood is not the largest among all the data. Thus, in these cases, prediction of the change in river-stage is a kind of interpolation of the training data.

In this study, we defined the output of the ANN as the change in river-stage, not the river-stage itself. Thus, the prediction of the largest flood could come down to the interpolation problem, and result in the good prediction accuracy.

\subsection{Calculation Time}

The computer used for testing had two CPUs with Intel ${ }^{\circledR}$ Xeon ${ }^{\circledR X}$ X690 (6-Core 3.46GHz) and 96GB (DDR3) memory. The compiler was Inter Composer XE 2011 Linux Edition (C++ ). Though it took several hours for training of the deep neural network, training can be done in advance. Since the 6 hours prediction calculation was about 0.1 second, the cost required for the real-time prediction calculation is slight.

\section{Conclusions}

In this study, we developed the real-time river-stage prediction model using deep learning, and confirmed its applicability in real rivers. The 6 hours river-stage level prediction showed good accuracy. In general, it is said that the ANN model cannot be guaranteed to inexperienced floods, but this study proved that there is a sufficient possibility for the accurate prediction in such case. 


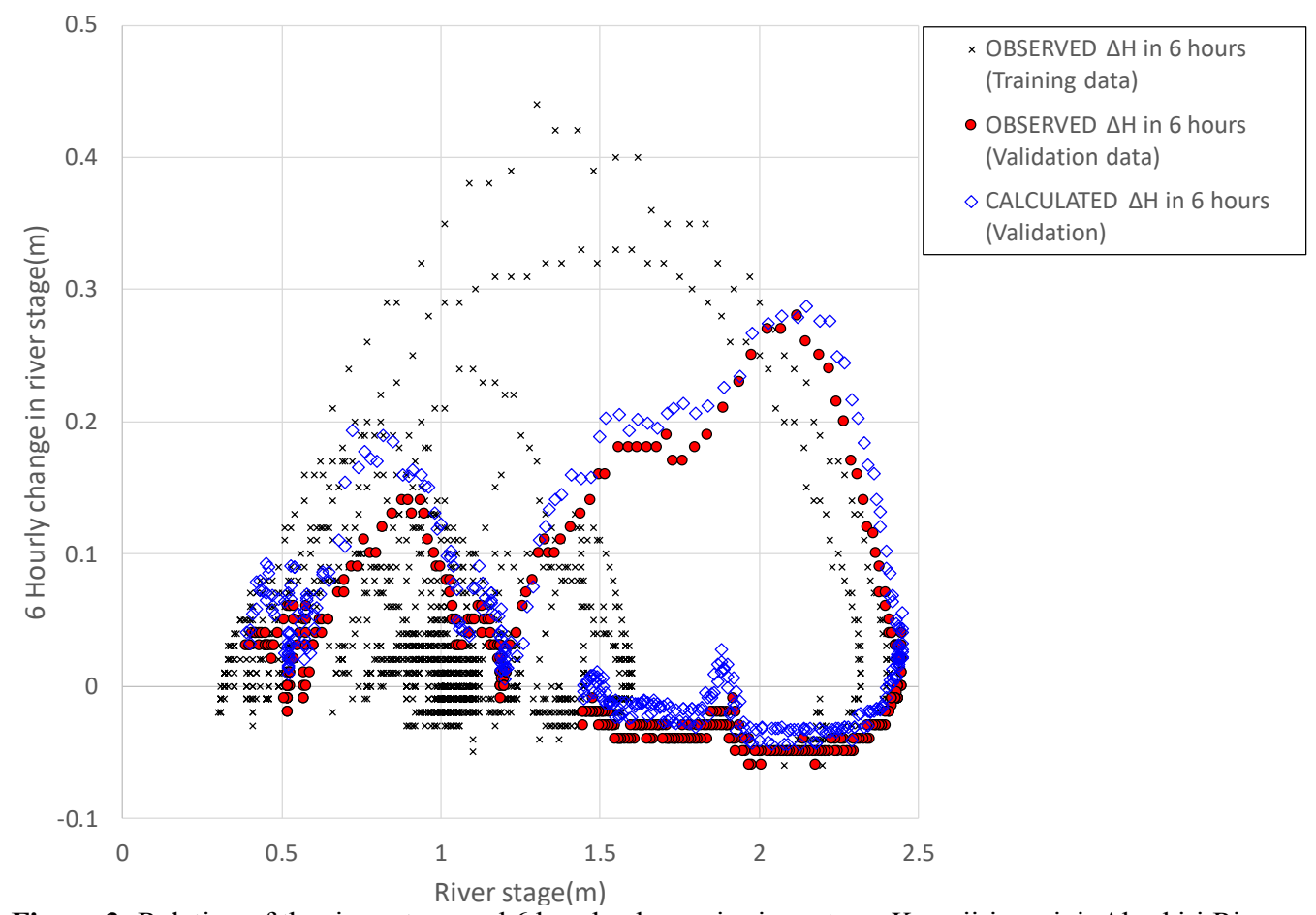

Figure 3: Relation of the river-stage and 6 hourly change in river-stage, Kawajiri-gyojoi, Abashiri River

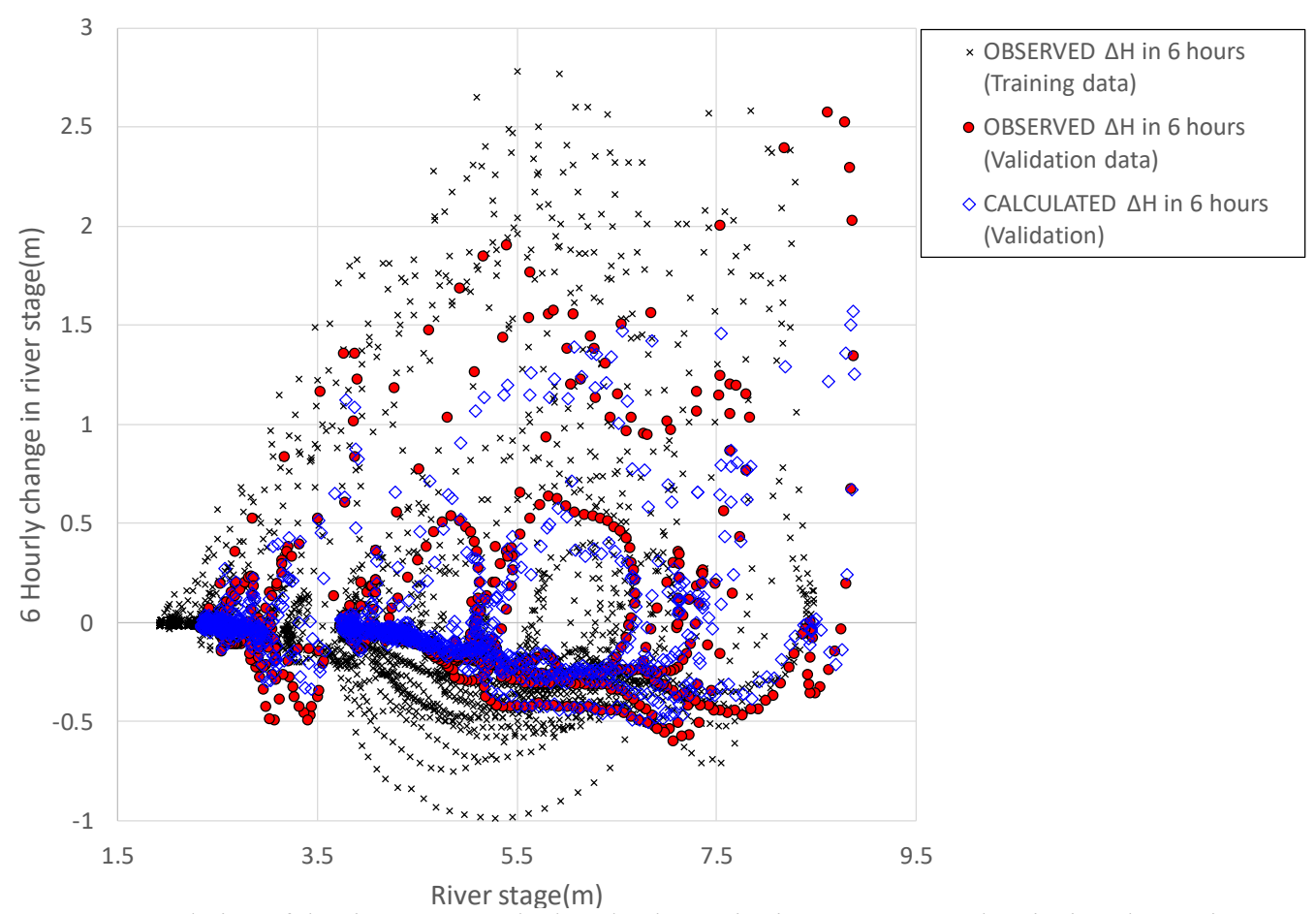

Figure 4: Relation of the river-stage and 6 hourly change in river-stage, Kawakamizoi, Tokoro River 


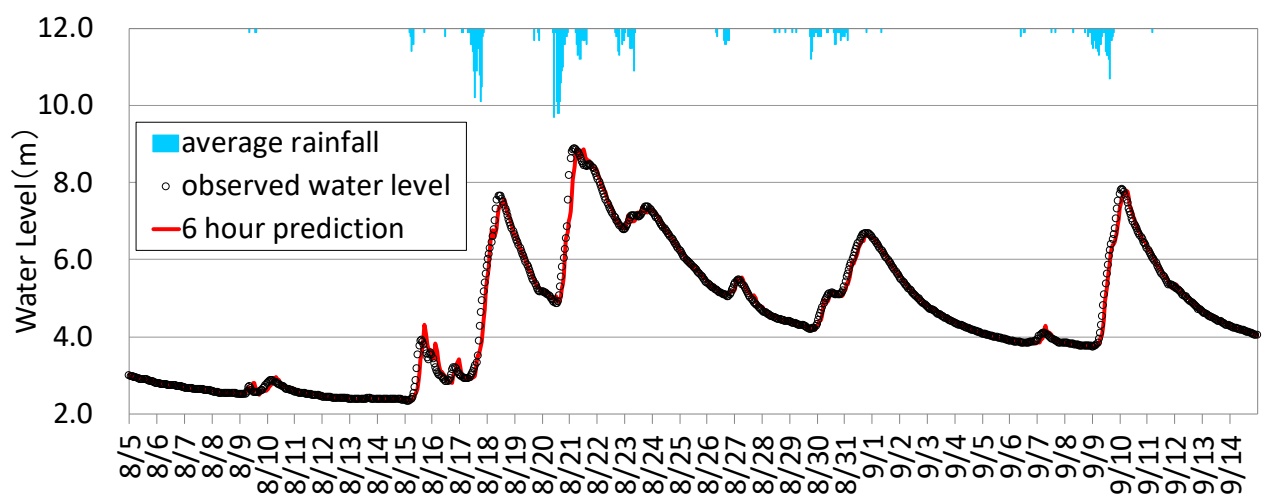

0

20

40

60

80

100

Figure 5: Result of 6 hours water level prediction of Kawakamizoi, Tokoro River (2016)

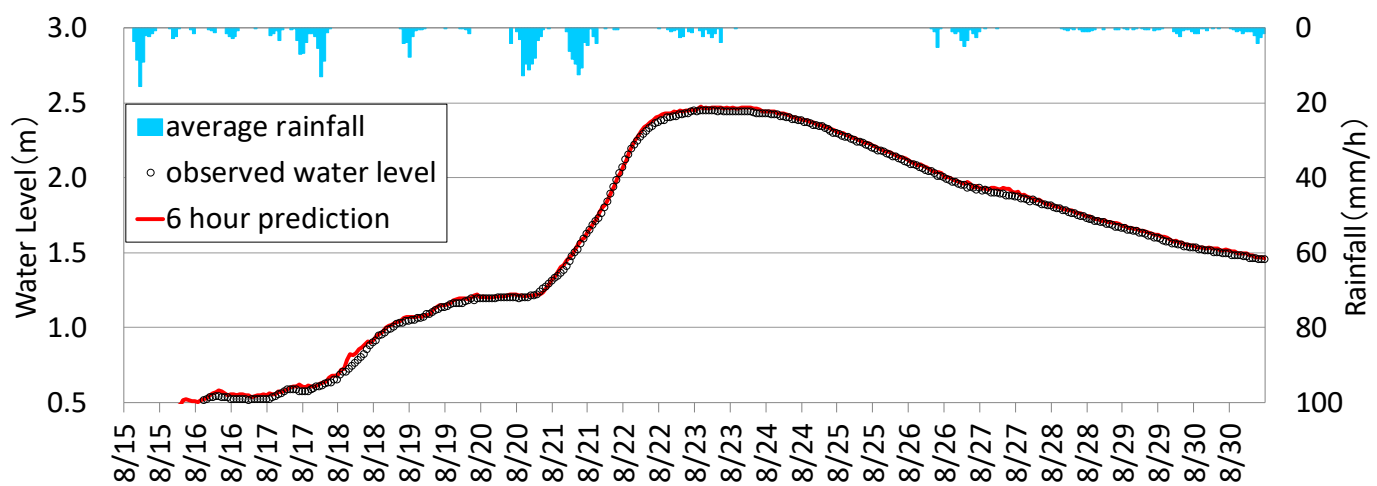

Figure 6: Result of 6 hours water level prediction of Kawajiri-gyojoi, Abashiri River (2016)

\section{References}

ASCE Task Committee on Application of Artificial Neural Networks in Hydrology: Artificial neural networks in hydrology. II : Hydrologic Applications, Journal of Hydrologic Engineering, Vol.5, No.2, (2000), pp.124-137.

C. W. Dawson, R. L. Wilby, Hydrological modelling using artificial neural networks, Progress in Physical Geography, Vol.25, No.1, (2001), p80-108.

H. R. Maier, A. Jain, G. C. Dandy, K. P. Sudheer, Methods used for the development of neural networks for the prediction of water resource variables in river systems: Current status and future directions, Environmental Modelling \& Software, Vol.25, 2010.

G. E. Hinton, S. Osindero, Y. Teh, A fast learning algorithm for deep belief nets, Neural Computation, Vol.18(2006), pp.1527-1544.

M. Hitokoto, M. Sakuraba, Y. Sei, Development of the Rearl-time river stage prediction method using deep learning, Journal of JSCE, Vol.5, No.1, (2017), pp. 422-429.

Rumelhart, D. E. and McClelland, J.: Parallel Distributed Processing: Explorations in the Microstructure of Cognition, MIT Press, 1986. 